\title{
artículos
}

\section{La gestión de la ciudad histórica en la Roma fascista 1: la instrucción sobre restauro urbano a través de la obra de Gustavo Giovannoni**}

Belén Calderón Roca

Investigadora vinculada a la UMA

PALABRAS CLAVE: Urbanismo/ Arquitectura/ Restauración/ Historiografía/ Italia

"Pero hoy, ¿dónde mirar? Un golpe mismo hiere al César y a Dios. Sorda carcoma prepara el misterioso cataclismo, y como en tiempo de la antigua Roma, todo cruje, vacila y se desploma en el cielo, en la tierra, en el abismo". GASPAR NUÑEZ DE ARCE, Gritos de Combate, 1870.

"Explicar y hacer comprender lo que pretendemos, no es cosa fácil, pues jamás se comprende lo que es nuevo, sino por analogía con lo que es viejo". FRANCIS BACON. Novum Organum, 1892.

RESUMEN

La dicotomía existente en el contexto italiano respecto a la instrucción de la arquitectura (canalizada hacia la restauración arquitectónica) entre la Scuola di Applicazione per gli Ingegneri y el Istituto di Belle Arti constituyó el germen de las máximas del restauro urbano. Hay que destacar la importancia de dos personalidades clave en este aspecto: Gustavo Giovannoni y Marcello Piacentini (al cual dedicaremos una segunda fase de este artículo). Escritor prolífico, la obra del arquitecto-urbanista-historiador de la arquitectura resultó decisiva para consolidar un método y una disciplina sobre el estudio de la historia de la arquitectura, la urbanística y la restauración de monumentos. El autor condujo su trayectoria didáctica hacia la salvaguardia del patrimonio monumental y la valoración de la figura profesional del arquitecto, cuya formación histórica resultaba determinante e imprescindible en los estudios de Arquitectura. Debemos destacar igualmente un peso decisivo en la divulgación de teorías y su contribución a la aparición de una nueva legislación en materia urbanística.

ABSTRACT

The existent duality in the italian architectural restauration context, in relation to the architecture restoration education between the Scuola di Applicazione per gli Ingegner (University College of Engineers) and the Istituto di Belle Arti (Art Institute) was the begining of the rules of the urban restauration theory. Gustavo Giovanonni has had a great importance in the teaching about the protection of the european historical city in first middle of the $X X$ century. Architect-town planner and arquitectural historian. Teachs in an important way: the safeguard of the monumental patrimony and show the importance of the historical architects formation. His activity was decisive to consolidate a method and a discipline for the study of the history of the architecture, the town planning and the restoration of monuments, also in the diffusion of theories and legislation about storical cities restaurations.

* CALDERÓN ROCA, Belén: "La gestión de la ciudad histórica en la Roma fascista 1: La instrucción sobre restauro urbano a través de la obra de Gustavo Giovannoni", Boletín de Arte $\mathrm{n}^{\circ} 28$, Departamento de Historia del Arte, Universidad de Málaga, 2007, págs. 253-277. 


Q articulos Belén Calderón Roca

INTRODUCCIÓN.

Podríamos decir que no ha sido hasta la década de los años ochenta del pasado siglo cuando se nos ha ofrecido una visión verdaderamente crítica de la obra de Gustavo Giovannoni (1873-1947) [1]. A pesar de la opacidad que mantuvo durante largo tiempo su figura, bien es cierto que ésta fue eminentemente contradictoria, ya que su formación en ingeniería civil contrastaba notablemente con su continuada actividad como historiador de la arquitectura y su confrontación con los historiadores del arte en cuestiones referentes al análisis científico de la arquitectura monumental y su destino público. Su obra resultó decisiva para consolidar un método y una disciplina sobre el estudio de la historia de la arquitectura, la urbanística y la restauración de monumentos.

Para determinar la importancia de este autor, basta pensar en su contribución al nacimiento de la Escuela de Arquitectura de Roma (Scuola Romana) en un entorno imperado por las Bellas Artes. Será precisamente en este ámbito de estudio y a partir de la década de los veinte, cuando dedicará mayores esfuerzos a definir el perfil cultural y profesional del arquitecto integral. Cientos de publicaciones avalan el carácter erudito de nuestro autor y su preocupación no sólo por los aspectos técnicos de la ciencia arquitectónica (dada su formación) sino además por los históricos y estéticos. En Giovannoni una nota cotidiana constituye la confrontación constante con la historia, que abarca desde la enseñanza de la arquitectura y la investigación sobre la restauración de monumentos, hasta las actuaciones y proyectos urbanísticos ex novo. Se preocupa por la figura profesional del arquitecto y la organización de ésta en el tiempo, poniendo de relieve las diferentes relaciones entre las posiciones culturales y profesionales. Al hilo de lo anterior, nuestro protagonista enfatiza la importante labor que desarrolla la Associazione fra i Cultori d'Architettura en Roma en la última década. Acusado de ser un conservador a ultranza, aunque más bien su postura se encuentra a caballo entre los principio violletianos y las teorías de Camillo Boito, reflexiona a través de sus escritos y aportaciones en distintas publicaciones sobre la restauración de monumentos y "teoriza" la Scuola Romana a través de su Dirección, cultivando la continuidad entre el presente de la ciudad y una cierta historia nacional.

Continuando esta línea de reflexión, debemos destacar un peso decisivo en la divulgación de teorías y su contribución a la aparición de una nueva legislación en materia urbanística: la Legge Urbanistica di 1933. Si bien, su aplicación durante el Fascismo no resultaría demasiado efectiva, no sería hasta bien pasados unos años (concretamente hasta la entrada en vigor de la ley de 1942) cuando su influencia afectará en gran modo a las acciones de conservación de bienes arquitectónicos y ambientales. 


\section{Q E artículos La gestión de la ciudad histórica en la Roma Fascista 1...}

Desde esta perspectiva, no podemos obviar la formulación de la mano de Camillo Boito, del primer compendio doctrinario para la restauración de monumentos, que años más tarde sería revisado y reelaborado por el propio Giovannioni en la Carta del Restauro italiana de 1931. Este documento se redacta en Roma en el seno del Consejo Superior de Antigüedades y Bellas Artes como consagración y sistematización oficial de las teorías de Giovannoni. Su finalidad fue unificar la metodología de restauración en las Superintendencias (Soprintendenze), y ofrecer a la vez, pautas a los arquitectos que ejercian libremente su profesión. Supuso uno de los grandes logros referentes a la elaboración y adopción de ver-

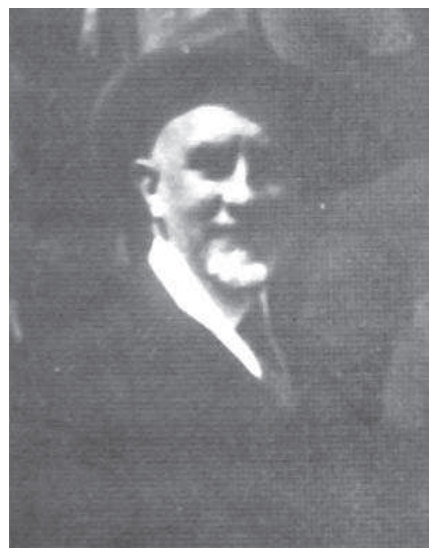
rentes a la elaboración y adopción de verrestauración a nivel internacional, promulgando pautas generales sobre tutela, conservación y restauración del patrimonio, que se harán factibles y deberán ser adoptadas por todos los Estados. En conexión con los aspectos que atañen a los centros históricos, en esta carta se repiten sustancialmente las formulaciones de la Carta de Atenas de 1931, afrontando el problema de la conservación del paisajey el ambiente de la ciudad histórica, dictando recomendaciones para respetar la fisonomía de los entornos monumentales ${ }^{1}$.

Nuestro autor delineará por vez primera el concepto de ambiente, constituido por la arquitectura menor circundante al monumento y su radical importancia, más

\footnotetext{
${ }^{* *}$ Las traducciones de los textos en italiano que se recogen en este trabajo, han sido realizadas de forma libre por la autora.

1 "Che siano conservati tutti gli elementi aventi un carattere d'arte o di storico ricordo, a qualunque tempo appartengono, senza che il desiderio di unità stilistica e del ritorno alla primitiva forma intervenga ad escluderne alcuni a detrimento di altri, e solo possano eliminarsi quelli, come le murature di finestre e di intercoIunni di portici che, privi di importanza e di significato, rappresentino deturpamenti inutili; ma che il giudizio di tali valori relativi e sulle rispondenti eliminazioni debba in ogni caso esere accuratamente vagliato, e non razen vagliato, e non imesso ad un giudizio personale dell'autore di un progetto di restauro". ("Que sean conservados todos lo elementos dotados de un valor artístico o histórico, pertenecientes a cualquier época; sin que el deseo de unidad estilística y de retorno a primitivas formas, excluya determinados valores en detrimento de otros, solo puedan eliminarse aquéllos, como las paredes de ventanas o los intercolumnios de pórticos, que privados de importancia o significado, su existencia resulte inútil; y que el criterio de estimación de tales valores relativos, así como su correspondiente eliminación sea convenientemente evaluado sin someterse a juicios personales en un proyecto de restauración").Carta italiana del Restauro, 1932, punto V.
} 
que como simple aparato decorativo de la arquitectura monumental, como terreno innato para la continuidad de lo antiguo en coexistencia con lo nuevo.

\section{EL MÉTODO PARA LA HISTORIA DE LA ARQUITECTURA.}

Personalidad clave del Novecientos italiano, su formación inicial proviene de la Ingeniería Civil. Obtuvo la Laurea o licenciatura en 1898 en la Scuola di Applicazioni per Ingegnieri di Roma y seguidamente un curso de especialización en Higiene Pública lo proyectó hacia lo que pareció ser un terreno científico-técnico. Durante este primer período, Roma asistía a la sucesión de unos acontecimientos que se desarrollaban de un modo vertiginoso. La adaptación a las nuevas exigencias culturales y ambientales se tradujo en precipitadas e irreflexivas operaciones de expansión urbanística que cristalizaron en drásticas operaciones de cirugía urbana, inaugurando nuevos ejes viarios y abriendo vía fácil a la especulación. En la creencia tradicional se había formado un dualismo entre "lo viejo" y "lo nuevo", y un antagonismo entre el progreso tecnológico y el racionalismo por un lado, y las motivaciones sentimentales ligadas a la historia y la defensa del pasado por otro, que se traducían en acciones como demoler o proteger, y salvaguardar ${ }^{2}$. Esta situación y su pasión por el ambiente romano incitarán a nuestro autor a plantearse el destino de la ciudad antigua, creyendo firmemente en las posibilidades de recuperación del patrimonio arquitectónico romano tras las desafortunadas actuaciones del piano urbanístico de 1883.

En el período 1897-1899 Giovannoni asiste a los cursos de historia medieval y moderna organizados por Adolfo Venturi en la Facultad de Letras de Roma. Junto a algunos compañeros ingresa en 1903 como miembro de una especie de centro de estudios o sindicato del cual tras algunos años más tarde aparecerá como líder indiscutible. Se trata de la Associazione Artistica fra $i$ cultori di architettura (A.a.c.a.r.). Esta corporación de arquitectos heredada de los collegia del mundo romano, nació en 1891 con vocación de reivindicar un estatus didáctico y profesional de la profesión de arquitecto (de larga tradición en países anglosajones) y hasta su desaparición en 1932 condujo su trayectoria hacia el diseño de una nueva figura del arquitecto como técnico y como artista "...promuovere lo studio e rialzare il prestigio dell'architettura..."3.

En Italia el libre ejercicio profesional y la formación autodidacta de los arquitectos implicaban la necesaria firma del ingeniero para cualquier actividad edificatoria de carácter público o privado.

2 Los adalides de las demoliciones y defensores de las formas radicales de cirugía edilicia eran llamados nuovatori, mientras que los defensores de la salvaguardia de los viejos vestigios se consideraban conservatori. 3 ("Promover el estudio y realzar el prestigio de la Arquitectura"), en Anuario della Associazione Artistica fra i Cultori di Architettura, nº 1 , art. 2. 


\section{․․ a a tículos La gestión de la ciudad histórica en la Roma Fascista 1...}

Las administraciones comunales no disponían de ninguna oficina técnica con personal que asumiese el rol de arquitecto, y sólo inscribían a ingenieros con alguna concreta especialización y varias atribuciones de carácter técnico y tecnológico ${ }^{4}$. La Asamblea de la A.a.c.a.r. con fecha 10 de enero de 1907, ya adelanta la absoluta necesidad de crear una verdadera enseñanza de la Arquitectura en Italia, exhortando la autonomía -al menos en materia teórica- de las escuelas superiores de Arquitectura respecto a los demás organismos de enseñanza superior. Asimismo, apela a la concesión de un papel predominante de la preparación artística y alienta a la creación de programas y escuelas adaptados a ambientes artísticos en conjunción con los estudios de carácter tecnológico y científico ${ }^{5}$.

Durante este período el joven Giovannoni comienza a frecuentar los círculos de erudición historiográfica y resulta clave mencionar que lo hace en un momento histórico en cual se hace efectiva la plena y completa institucionalización de la historia del arte italiana ${ }^{6}$. La investigación de la historia del arte (y con ella la de la arquitectura $)^{7}$ atraviesa un momento de plenitud a la búsqueda de sólidas bases metodológicas y directrices formativas, en contraposición al diletantismo artístico anterior predominante. Los cursos de historia del arte a los que asiste y su asidua presencia en tertulias filológicas y arqueológicas amplían en profundidad su bagaje cultural para cimentarse en este terreno. En lo que a la historia del Arte se refiere, Venturi constituye el verdadero punto de referencia en el cual se inspira Giovannoni y ello se evidencia en su primer artículo escrito para L'Arte en 1908, en el cual expone las líneas de un método básico sobre la eficacia del examen crítico directo de la obra de arte: "il criterio veramente racionale di critica di una qualunque manifestazione artistica debe essere l'essame directo di essa e lo studio completo analitico e sintetico delle sue forme e del concetto che le avvia"8. La intervención de Giovannoni en el Congresso Internazionale di Scienze Storiche de 1903 constituye el último escalón

4 GIOVANNONI, G.: Gli architetti e gli studi di architettura in Italia, Tipografía dell'Unione Editrice, Roma , 1916, págs. $26-27$

5 GIOVANNONI, G.: "Relazione della Commissione per le scuola di architettura" en Anuario della Associazione Artistica fra i Cultori di Architettura, Società Editrice Laziale, Roma, 1908, págs.24 y 28-29.

6 La escuela de perfeccionamiento en Historia del Arte se inaugura en el curso 1896-97 como nexo de unión entre la Universidad y la instauración de la Sovrintendenze alle Belle Arti. Posteriormente, la $1^{\circ}$ Cátedra de Historia del Arte italiana se establecerá en 1901, tras el logro del proyecto de Adolfo Venturi de dar forma estable a una disciplina universitaria adherida al aparato administrativo. Venturi comienza a brindar estímulos para desarrollar métodos de elaboración de conceptos sobre el uso de la historia, que en realidad no eran sino un criterio general de trabajo. Vid. VENTURI, L.: Storia della critica d'arte, Einaudi, Torino, 1964.

${ }^{7}$ No debemos olvidar la complejidad existente en este tema respecto a las analogías y disonancias que tropiezan entre dos contextos: el italiano y el español; y respectivamente, dos sectores profesionales si bien, estrechan directo del objeto material en la fabica historica y de la teorla de la arquitectura, e historiadores del Arte, cuya tarea en el contexto español es investigar y reflexionar sobre todas las artes, pero que exceptúa a la arquitectura en el italiano.

8 "El criterio verdaderamente racional de crítica de cualquier manifestación artística, debe ser el examen 
que lo separa de la definición de un método completo útil para el historiador de la arquitectura ${ }^{9}$. En aquella ocasión afronta el problema de la restauración de monumentos subrayando la necesidad de adquirir habilidades en el manejo de fuentes historiográficas, y contemporáneamente, proceder al examen directo de la obra de $\operatorname{arte}^{10}$.

A partir de aquí se instaura el "método positivo"11, que pone de manifiesto la importancia que se desprende de la observación directa de las fábricas, que deberán unirse al vaciado de fuentes documentales. En el itinerario acaecido en los estudios de arquitectura en Italia, desde las escuelas de Bellas Artes a las facultades de arquitectura, la figura del arquitecto civil y la del profesor de diseño quedan superadas y la necesidad de reunir enseñanza artística y técnica es sostenida por Giovannoni, el cual preconizará lo que deberá ser una nueva figura profesional: el "arquitecto integral", ante todo defensor del dato histórico como fundamento de cualquier acción de valorización de monumentos "qualsiasi progetto debe necesariamente misurarsi con la presenza, evidente come in nessun altro luogo, della storia"12.

Giovannoni reflexiona acerca de la idoneidad de la Historia de la arquitectura aplicada a elaborar un corpus teórico para afrontar acciones de restauración arquitectónica. Como eje central del discurso sitúa a la historia de la Arquitectura, escrita hace poco y en modo más embrionario, la cual resulta todavía compleja y multiforme, ya que está ligada a condiciones positivas de utilidad y de materiales según las exigencias de la vida social y civil que refleja ${ }^{13}$. En virtud de esta premisa, la Historia

directo de ella y el estudio completo analítico y sintético de sus formas y del concepto que supone". GIOVANNONI, G.: "La porta del palazzetto Simonetti in Roma", in L'Arte, $n^{\circ} 1, n^{\circ} 6-9$, Grafiche Italiane Stucchi, Milano, 1908, págs. 368-373.

9 La definición de un método completo para la historia de la arquitectura aparecerá por vez primera en 1904, en su estudio sobre los monasterios benedictinos en el Valle de Aiene Vid.: EGIDI, P., GIOVANNONI, G., HERMANIN, F. y FEDERICI, V. (a cura di): "L'architettura dei monasteri Sublacensi", en I monasteri di HERMANIN, F. y FEDERICl, V. (a cura di): "L'architettura dei monasteri Sublacensi", en I monasteri di
Subiaco, vol I, Roma, 1904.

10 GIOVANNONI, G.: I Restauri dei monumenti ed il recente congresso storico", Bollettino della Società degli Ingegnieri e degli Architett Italiani, XI, nº 9-16 (19 aprile), 1903, págs. 166 y ss.

11 La interpretación positivista se funda sobre observaciones empíricas y sobre la técnica de la experimentación, que debe ser necesariamente integrada y absorbida por la cultura histórica en base a futuros estudios sistemáticos que sean coherentes y penetren concretando cada situación de hecho. SAMONÀ, G. "Positivismo e storicismo nella cultura urbanística di oggi", en Casabella, n 200, febrero-marzo, Milano, 1954 pág. 43.

12 "Cualquier proyecto debe necesariamente medirse con la presencia evidente como en ningún otro lugar, de la historia". Giovannoni confía en la posibilidad de conseguir formar el "arquitecto integral", aunque lógicamente predominarán algunas tendencias sobre otras según la formación inicial del profesional en cuestión. Este deberá tener el siguiente bagaje: una vasta cultura general; saber estudiar de modo autodidacta, es decir, ponerse al corriente de los nuevos avances científicos y sus aplicaciones, así como preparación científica en el campo de las construcciones civiles comparable a la del ingeniero; un conocimiento profundo de la Historia del Arte y de la historia de la Arquitectura, que le facilite el conocimiento, más que de las formas, del mismo espíritu del significado de los diversos períodos de arte precedentes; una preparación artística completa que sepa alternar entre todas las diferentes artes, habilidad práctica en la representación, conoce los medios decorativos, etc.; y finalmente, resultará imprescindible la experiencia de construcción, gestión y administración. GIOVANNONI, G.: Gli architetti... Op. Cit., págs. 11-12. 
podrá servir de provecho siempre y cuando sea posible evaluar minuciosa e imparcialmente causas y consecuencias sin caer en el equívoco de hacer literatura ${ }^{14}$.

En otro orden de cosas, puede llamar la atención que en Giovannoni aflore demasiado a menudo su visón tecnicista y discrepe abiertamente con los adeptos al conservacionismo, a quienes llama despectivamente "fetichistas del pasado", y entre los que engloba a los arqueólogos, historiadores del arte y doctos en historia local ${ }^{15}$.

En honor a la verdad, la historia que se impartía es esa fecha en la escuela de arquitectura de Roma resultaba más bien un repertorio de formas, donde el estudio de fechas no resultaba indispensable y el verdadero protagonista era el dibujo. Los intereses históricos de Giovannoni se reconcilian en sus teorías a través de la interpretación personal que realiza de la restauración arquitectónica, recuperando estructuras filológicas que evolucionan hacia la planificación global y la restauración territorial integral ${ }^{16}$. No obstante y hasta cierto punto, el conocimiento filológico se mantiene bastante distante en la realidad práctica, pues al fin y al cabo, no podemos olvidar que se trata de un ingeniero que ha recibido una formación sucinta en Bellas Artes. ${ }^{17}$. Secundando lo expuesto, quizás podríamos exprimir que, Giovannoni pretende arrebatar la historia de la arquitectura a los historiadores del arte y estudiar la arquitectura italiana según nuevos criterios. Como elemento fundamental del ambiente construido, la arquitectura tradicionalmente ha mostrado de si misma unas visiones aisladas y parciales, fragmentarias e imperfectas, y ésta se debe estudiar bajo nuevos criterios por sentido global y amplísimo, naturalmente diversa en su concepción al resto de las Bellas Artes. "...la architettura é sintesi di arte e di tecnica (...)“...la tecnica, che nelle arti é mezzo..., ma servo del pensiero artistico, nella architettura trovasi in inmediato rapporto con lo stesso scopo positivo dell'opera, che é di elevare fabbriche utili valendosi di materiali e di procedimenti concreti"18, es decir, reivindicando una historia de la arquitectura italiana estudiada sólo por arquitectos.

Llegados a este punto, se patentiza abiertamente la eterna discusión entre la

13 DI STEFANI, L.: Le scuole di architettura in Italia. Il dibattito dal 1860 al 1933, Franco Angeli, Milano, 1992 pág. 143 y ss.

14 GIOVANNONI, G.: Gli architetti... Op. Cit., pág. 8.

15 VENTURI, A: "Sul metodo della Storia dell'architettura", en L'Arte, anno XLI, Fasc I, Vol. 9, Grafiche Italiane Stucchi, Milano, 1938, pág. 370.

16 DEL BUFALO, A.: Gustavo Giovannoni. Note e osservazioni integrate dalla consultazione dell'archivio presso il Centro di Studi di Storia dell' Architettura, Kappa, Roma, 1982, pág. 110.

17 Respecto a estas cuestiones Piccinato califica a su ex-docente de "una ignorancia espantosa". NICOLOSO, P.: Gli architetti di Mussolini. Scuole e sindacato, architetti e massoni, proffessori e politici negli anni del regime, Franco Angeli, Milano, 1999, págs. 80-81.

18 "La arquitectura es la síntesis de arte y técnica (...) la técnica, que en las artes es medio, ...aunque se sirve del pensamiento artístico, en la arquitectura encuentra un ainmediata relación con el mismo objetivo positivo de la obra, que es enaltecer construcciones útiles valiéndose de materiales y de procedimientos con- 
formación de los historiadores del Arte y la de los arquitectos en materia de historia arquitectónica en Italia. El entendimiento inicial entre Giovannoni y Venturi desemboca por estas fechas en mutuas invectivas acerca de lo que debía ser la correcta labor de historiador de la arquitectura. El primero acusa al segundo de clasificar y documentar la arquitectura según la metodología estilística, es decir, por medio de los mismos criterios que se usan para la historia de la pintura y escultura19. Venturi refuta a Giovannoni: “..stà fuori strada nella cogizione vera del monumento" (Está fuera de lugar en la verdadera comprensión del monumento), pues carece de un "método positivo" en el estudio de una obra con carácter positivo, que es la arquitectura, pues tal vez, pretende excluir del estudio del arte arquitectónico aquellos procedimientos y que no se computan con escuadra y compás. A lo que Giovannoni responde: en la lectura de un documento, sea arquitectónico o pictórico, debe existir un intercambio de criterios, distinguir entre: construcción y arquitectura; práctica y arte; y sentir el toque del artista en lo particular, el detalle, para comprender la totalidad. En virtud de estas premisas, no tardaría en emitir la correspondiente réplica nuestro protagonista. Giovannoni alienta a los arquitectos a asumir el liderazgo frente a los historiadores y arqueólogos, aunque colaborando con ellos, no como subordinados, sino como colegas que compensan entre sí las respectivas deficiencias de sus disciplinas "Hoc opus hic labor" (en ésto reside lo complicado de esta tarea) ${ }^{20}$. Afirma que el siglo XX es deudor de una censurable herencia en lo que afecta a la teoría de la arquitectura, especialmente en Italia, que se ha visto invadida por un internacionalismo arquitectónico paralelo al nacionalismo político.

Giovannoni conduce su trayectoria didáctica hacia una precisa y fundamental orientación: la salvaguardia del patrimonio monumental y la valoración de la figura profesional del arquitecto, cuya formación histórica resulta determinante e imprescindible en los estudios de Arquitectura como punto de partida para establecer los criterios de actuación en la profesión. En Giovannoni el "momento histórico" se configura como una realidad que el hombre construye permanentemente con múltiples elementos, conformando una totalidad con diversos nexos entre sí que no pueden ser valorados aisladamente. La posterior clasificación de las transformaciones acaecidas en el transcurso del tiempo definirá un determinado tipo constructivo, y éstas serán consideradas como las causas permanentes de su ambiente, es decir, habrán determinado la topografía y la morfología de los edificios.

En cualquier caso, y pese a que Giovannoni se empeña en rechazar la elabo-

cretos". GIOVANNONI, G.: "II metodo nella storia della architettura" en Palladio III, , Istituto Poligrafico e Zecca dello Stato, Roma 1939, pág. 77.

19 VENTURI, A.: "Sul metodo... Op. Cit., págs. 373.

20 GIOVANNONI, G.: La figura artística e professionale dell'architetto, Sindacato Nazionale Architetti, Le Monier, Firenze, 1929, pág. 25 


\section{- a áteulos La gestión de la ciudad histórica en la Roma Fascista 1...}

2. Gustavo Giovannoni (a la dcha) junto a Antonio Muñoz y Corrado Ricci.

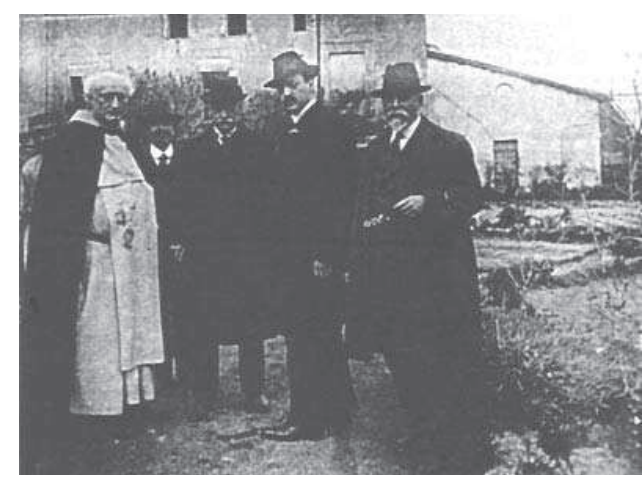

ración de grandes doctrinas, el empeño por confeccionar un método positivo para analizar los materiales de la historia, constituye sin duda el germen de una posible teoría del restauro que se confirmará con la promulgación de la Carta italiana del Restauro de 1931. Tras su incorporación en 1912 como profesor en la Escuela de Arquitectura, Giovannoni delibera sobre el problema que subyace en la verdadera y correcta enseñanza de la disciplina. En un momento político en el cual falta personal preparado para afrontar las obras de reconstrucción arquitectónica, Italia es y todavía mucho, el país de las Academias, y se ha creado un lecho de discusión sobre si la arquitectura constituye un arte o una ciencia. Coincidiendo con esta fecha, participa en un Convenio Nacional sobre inspectores de excavaciones y monumentos y delinea las bases de una teoría que permanecerá inmutable a lo largo de todo el pensamiento giovanniniano [2]. Un método completo en materia de arquitectura y restauración que describirá las actitudes a tener en cuenta en la valoración de monumentos: historia, crítica y tipos y fases de intervención ${ }^{21}$, que no duda en publicar a través de numerosos trabajos y la redacción de algunos planes de restauración, como el proyecto de aislamiento del Foro Boario en Roma y la posterior redacción del Piano Regolatore de 1931.

En 1915 ingresa en el Consejo Superior de Antigüedad y Bellas Artes como inspector, labor que desempeñará durante más de veinticinco años, colocándose así en el punto de mira de las cuestiones sobre restauración urbana de toda Italia. Esta posición favorece la continuidad y profundización de sus investigaciones desde la óptica poliédrica de un arquitecto proyectista, historiador de la arquitectura y técnico

21 GIOVANNONI, G.: "Restauri di monumenti" (Conferenza di Gustavo Giovannoni) en Bollettino d'Arte Ministero della Pubblica Istruzione, nº 1-2, Anno VII, E. Calzone Editore, Roma, 1913, págs. 2-42. 
de la Administración. La opinión de Giovannoni sobre lo poco acertado que fue hasta su llegada la gestión de Roma en lo relativo a cuestiones de coordinación del desarrollo del antiguo centro, no dejaba lugar a dudas. Nuestro autor examina los defectos de los que adolece la actual organización de los entes gestores de la ciudad histórica, que tienen como elementos principales los uffici regionali para la conservación de monumentos. Estas instituciones no presentaban ninguna unidad en la dirección del sistema directivo, es decir, se caracterizaban por una total ausencia de coordinación en las provisiones, que junto al vasto campo de acción (ya que algunos de ellos se hacían cargo además de la tutela del resto de Bienes Artísticos), se unían la carencia de fondos y un vacío absoluto en conceptos claros respecto a las exigencias a las cuales el personal debía hacer frente. Junto a estas cuestiones se arrastraban problemas que dificultaron el último período de desarrollo romano: irregular conformación altimétrica, pobreza financiera, existencia en el centro de la gran zona arqueológica de los foros y del Palatino... El planteamiento de Giovannoni giraba en torno a la idea de que los funcionarios tendían a resolver problemas relativos a los viejos barrios históricos como si fuesen un problema ordinario de la Administración ${ }^{22}$. Sin embargo la realidad era más ardua y compleja; en demasiadas ocasiones los errores se debían a la inexistencia de un meditado programa. Dice Giovannoni: “... En este campo habitualmente se improvisa demasiado y se toman decisiones con demasiada ligereza..."23 Las grandes dificultades surgen de la necesidad de una preparación profunda en los técnicos para afrontar con criterios efectivos cuestiones gravísimas que se acarreaban desde antaño. Por ello, a modo de continuidad, a través del planteamiento de formar a los técnicos de la Administración, proyecta la idea de instituir en el seno de la facultad de Arquitectura un curso post-licenciatura obligatorio para los funcionarios de la Soprintendenza ai Monumenti.

Como fruto de las experiencias vividas por Giovannoni en los órganos oficiales de tutela del patrimonio arquitectónico, será justamente desde la Administración, desde donde se lance diversas publicaciones que tratarán este aspecto. Cabe destacar una revista sobre el estudio de monumentos bautizada como Palladio. Puesta en marcha en 1932, a través de diversos artículos nuestro autor reexamina diversos episodios de restauración que adquirirán nuevos significados, reuniendo las prerro-

22 El grave peligro de la "modernidad" era que no existían por parte del funcionariado público ningunas ganas, ni predisposición a la reconstrucción. En cambio, las grandes constructoras (standard-types) preparadas desde grandes empresas y multinacionales eran preferidas para la reconstrucción nacional. GIOVANNO$\mathrm{NI}$, G.: Per la ricostruzione dei paesi italiani rovinati dalla guerra, Associazione Artística fra i Cultori di Architettura, Roma, 1918, págs.10-12.

23 GIOVANNONI, G.: "Vecchie città ed edilizia nuova. II quartiere del Rinascimento a Roma", en Direzione dalla Nuova Antologia, Roma, 1913, págs. 5-6. 
Q E a tículos La gestión de la ciudad histórica en la Roma Fascista 1...

gativas de conjugar la lectura de la fábrica con la sustancia histórica.

Por otra parte, en este período Giovannoni consolida la teoría que establece una fundamental distinción entre "monumentos vivos" y monumentos muertos", concepto que es rebatido en 1925 cuando publica una miscelánea de escritos dedicados al problema de la valorización de monumentos ${ }^{24}$, y establece los diferentes tipos de restauración. ${ }^{25}$. En 1935 es nombrado Académico de Italia, y a través de sus publicaciones en el Istituto di Studi Romani retomará el tema de las actuaciones del nuevo Piano Regolatore de Roma en cuanto a respeto por las tradiciones en el campo urbanístico.

LA teoría del Diradamento y El VALOR DEL Ambiente.

En óptima concreción de este trabajo, debemos señalar el importante papel que desempeña la ciudad de Roma en un momento histórico donde coexistieron dos universos particulares e inéditos en el tema de la arquitectura y la ciudad: la Universidad y las organizaciones profesionales. La dicotomía existente en la instrucción de la Arquitectura (canalizada hacia la restauración arquitectónica) entre la Scuola di Applicazione per gli Ingegneri y el Istituto di Belle Arti de Roma ponía de relieve las directas y constantes relaciones existentes entre el campo de la Ingeniería y el de las Bellas Artes. Cualquiera que pretendiese ejercer la profesión de arquitecto debía estudiar ingeniería y a la vez, frecuentar los cursos complementarios de algunas materias sobre Arquitectura en el Instituto de Bellas Artes. La escalada al poder de un grupo romano muy influyente en los ambientes ministeriales partió de un objetivo común: asignar a la sede capitolina prioridad en materia de arquitectura. La ciudad eterna, más que cualquier otro caso urbano representaba un campo ideal para el desarrollo de teorías y la síntesis de maniobras divergentes: transformar y conservar, modernizar y valorizar la identidad. Este particular período

24 CURUNI, A.: "Gustavo Giovannoni. Pensieri e principi di restauro architettonico", en CASIELLO, S. (a cura di): La cultura del restauro. Teorie e fondatori, Marsilio Ed., Venezia, 1996, págs. 286-287.

25 En primer lugar, encontramos el restauro de consolidación, al cual el autor confiere gran importancia. Se acepta la necesidad de tal acción únicamente en casos de garantizar la perdurabilidad del edificio, previo riguroso trabajo de estudio gráfico y material que garantice la eficacia de la actuación, y evite en lo posible menoscabar seriamente el carácter de la obra. A continuación encontramos las acciones de recomposición, consistentes en añadidos a la obra original desde la anastilosis, es decir, recuperando restos materiales y trasladándolos a su lugar de origen. En íntima relación con este punto aparece la restauración de ripristinación o completamento. Ésta permite recuperar parcial o totalmente la imagen del edificio mediante la adición de piezas (siempre en un porcentaje notablemente menor respecto del original) compuestas de materiales diferentes y distinguibles de los originales. La intervención de innovación se diferencia de la anterior clasificación por el rechazo de su uso siempre que no resulte estrictamente necesario. En cuyo caso se realizar con materiales distinguibles de los originales y por supuesto, cuando no incurra en la falsificación de estilo. Por último la intervención de liberación sólo se aceptará cuando el añadido a destruir carezca de valores y su desaparición no afecte a la comprensión ni a la autenticidad de su significado. GIOVANNONI, G. "Restauri di monumenti", Op. Cit. 
de la historia italiana asiste a la fundación de la primera y más importante escuela de arquitectura en un contexto y por consenso político, masónico. La Scuola Superiore di Architettura di Roma con sede en el Instituto di Belle Arti de Via Ripetta se instituye el 31 de octubre de 1919, y será Giovannoni quien pronuncie el discurso oficial de apertura de la escuela en $1920^{26}$. Nuestro protagonista comienza enseñando Historia y Estilos de Arquitectura y un curso más tarde se hace cargo de la enseñanza del curso Restauración de monumentos. En 1927 recibe el nombramiento como Director, cargo que desempeñará hasta 1935, cuando será destituido del puesto a favor de Marcello Piacentini. La docencia de la asignatura o corso di laurea, adiestraba en el ejercicio de la restitución ideal de los monumentos mediante el conocimiento de la historia y el dominio del proyecto, asumiendo este nexo una importancia central para la formación de un estilo nacional arquitectónico en continuidad con el pasado. Realmente podemos afirmar que Giovannoni es el único personaje verdaderamente teórico de entre todos los docentes de la escuela y que además proviene del mundo académico.

Algunas de las materias incluidas en los primeros cursos de la escuela de Arquitectura de Roma eran los Estilos Arquitectónicos y la Historia de la arquitectura, la Estética de la ciudad, Elementos de Arqueología, Historia del Arte y Restauración de monumentos. Con la introducción de la disciplina de la Estética de la ciudad, Giovannoni demostró un evidente interés por aspectos específicamente urbanistas de la arquitectura, sin detenerse en los monumentos aislados como veremos más adelante. En plena institucionalización de la Historia del Arte italiana, a partir del principio de ambiente, se mezclan y se funden problemas de restauro arquitectónico, tutela y valorización del patrimonio monumental junto a los problemas de ordenación urbanística en los viejos centros. Giovannoni rebate constantemente la idea de que el monumento pueda ser considerado de forma aislada; de la apreciación de un complejo arquitectónico (como obra de arte) dependerán: el espacio, las visuales, la concordancia o discordancia con obras menores, y también sus cualidades intrínsecas. Para él, independientemente a los modos en los cuales pueda ser reconstruido, aquel está inserto en un contexto que deberá ser valorado en su totalidad, y censura el sistema del viejo piano regolatore en cuanto a su permisibilidad a la hora de otorgar más valor a los edificios monumentales que al resto de agrupaciones menores de arquitectura vernácula27. La dimensión que adquiere la fase de investigación resulta formidable; ésta jamás deberá ser improvisada, pues el ambiente que se genera entre los

26 R. D. de 31 de octubre de 1919, no 2593 firmado por el ministro de la Pubblica Istruzione Alfredo Baccelli. NICOLOSO, P.: Gli architetti di Mussolini. Scuole e sindicato, architetti e masoni, professori e politici negli anni del regime, Franco Angeli, Milano, 1999, pág. 35.

27 GIOVANNONI, G.: "Restauro dei monumenti e urbanística”. En Palladio, n 2-3, XXI, Istituto Poligrafico e Zecca dello Stato, Roma, 1943. 
monumentos deberá conservarse armónico con el total de las masas y las líneas constructivas $^{28}$. Del mismo modo subraya la importante relación de la obra monumental con su entorno, ya que éste condiciona la interpretación del valor del monumento y expresa una valoración de la ciudad, heredando las máximas articuladas por Camillo Sitte respecto a la concepción de ésta como problema estético. La ciudad es ante todo una "cuestión de arte" en la cual se juzga negativamente la tendencia habitual de su época de liberar los monumentos, vaciando físicamente su entorno, pues la conservación del ambiente resulta brutalmente violada mediante propuestas de aislamiento y ampliación de visuales.

En líneas generales, Giovannoni defiende la aplicación de la teoría del diradamento, consistente en armonizar la conservación del entorno y los requerimientos de sustitución de las viejas estructuras arquitectónicas de la ciudad. Cada monumento, cada trama edilicia, constituye un caso clínico que presenta sus propios problemas. En el pensamiento de Giovannoni el organismo urbano se proyecta como una unitaria y coherente entidad, en la cual, se trata de sellar la compatibilidad entre lo nuevo y lo antiguo sin caer en el embalsamamiento de la ciudad eterna de arte o en la aniquilación de los vestigios pasados mediante drásticas operaciones quirúrgicas, al mismo tiempo que se satisfacen las necesidades de una gran metrópoli [3-4]. Junto a estos aspectos, proseguimos en el contexto universitario y encontramos en contraposición a su coetáneo Piacentini. Considerado un modernista "fanático", se ocupaba de guiar la proyección de la ciudad hacia las nuevas tendencias y buscar una vía italiana en la arquitectura como símbolo de la nación fascista. El planteamiento fue la drástica separación entre la ciudad vieja, pensada como repertorio de tesoros de arte, y la ciudad nueva, ligada a las funciones cotidianas y las necesidades modernas que comportaban la introducción de una nueva arquitectura; argumentando la conveniencia de trasladar el viejo centro urbano a otras zonas de ensanche de la ciudad (spostamento), aunque de ello hablaremos en un próximo trabajo.

En el umbral de los años treinta, en plena efervescencia fascista, parecen manifestarse evidencias palpables de disputas entre Giovannoni y Piacentini, que se corroboran con la creación del Instituto Nazionale di Urbanistica (INU) por este último y su inclusión en la revista Architettura e Arti Decorative" en torno al $1926^{29}$. Con la publicación de Vecchie città ed edilizia nuova con motivo de la redacción del plan de urbanismo para la ciudad en 1931, se confirma de este modo una auténtica supremacía giovannoniana respecto a la formulación de teorías en cuestiones de urbanística. En esta obra se proponen numerosos ejemplos y posibilidades de orde-

28 GIOVANNONI, G.: Per la ricostruzione... Op. Cit., pág. 9.

29 Con el posterior ascenso a la dirección de la revista de Marcello Piacentini, éste cambiará su orientación ideológica, así como el nombre por el de simplemente Architettura. 

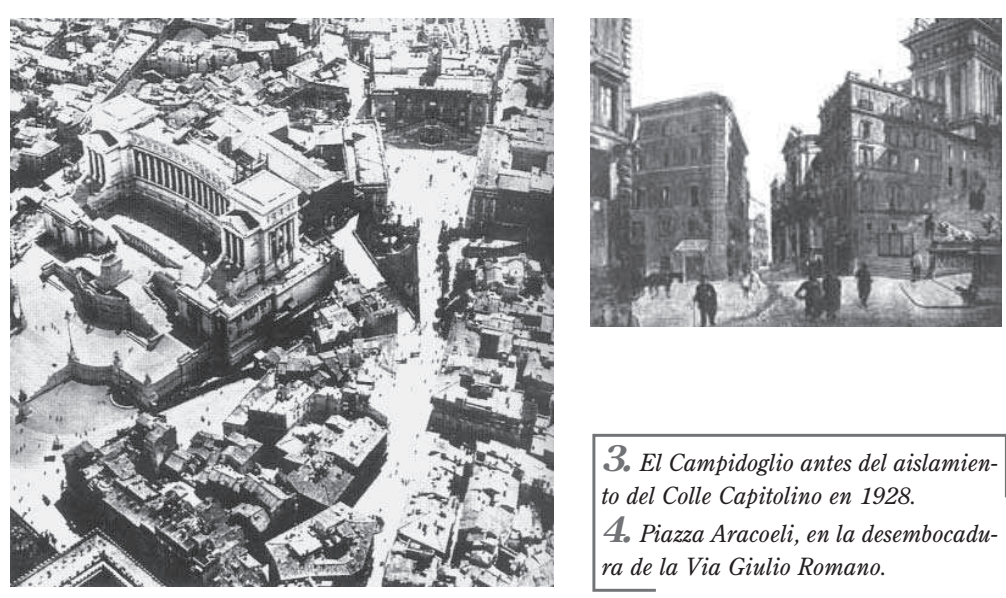

3. El Campidoglio antes del aislamiento del Colle Capitolino en 1928.

4. Piazza Aracoeli, en la desembocadura de la Via Giulio Romano.

nación urbana a través del principio del diradamento, liberando las entrañas de la urbe a través de la supresión de las antiguas murallas y procediendo a rehabilitar las zonas restantes (Risanamento).

El horizonte explicativo de este razonamiento pasa por la consideración de la siguiente metáfora: la población de los viejos barrios de la ciudad es similar a los árboles de un bosque; germinados en libre disposición natural, dispuestos según radios en largos espacios o bien, sutiles y finos hileros para morir en esquinas, o seccionados brutalmente por la piqueta. De cualquier modo, constituyen organismos que nacen de la misma raíz y se reproducen una y otra vez. Por ende, las casas se renuevan y transforman, se reconstruyen, pero rara vez varía del primitivo esquema edilicio, que sobrevive como "trama" del desarrollo sucesivo ${ }^{30}$ [5]. Con lo cual, los barrios del viejo centro representan casi un monumento colectivo, pues deviene un organismo constructivo que se reencuentra en las proporciones, en las formas, en los materiales de los que se compone y en las disposiciones escenográficas ${ }^{31}$. A menudo los barrios tienen un esquema de convergencia de monumentos y visuales reducidas que se tienden a ampliar; otras veces, existe una completa irregularidad de casas, calles y plazas reclusas como si fueran grandes salas entorno a los monumentos principales. Razones de defensa, adaptación a confines ya preexistentes o exigen-

30 El tema de la arquitectura menor constituye una de las principales trayectorias didácticas de Giovannoni en la Escuela de Roma: NICOLOSO, P.: Op. Cit., págs. 80-81.

31 GIOVANNONI, G.: Questioni di architettura nella storia e nella vita. Edilizia, estetica architettonica, restauri, ambiente dei monumenti, Società Editrice d’Arte llustrata, Roma, 1925, pág. 175. 


\section{- a artículos La gestión de la ciudad histórica en la Roma Fascista 1...}

cias de reunión popular, etc., fueron los motivos de tales construcciones, que respondían aun a determinados motivos de higiene y estética ${ }^{32}$.

En un ambiente creado existen edificios "menores" en los que se admite - por la ausencia relativa o por la poca identidad en confrontación con el total- cierta libertad a la hora de actuar urbanísticamente, ya que no representan la traducción en piedra de hipótesis o inducciones estilísticas. No obstante, es necesario prestar cuidado ciertos sectores donde pueda considerarse el "artificio", es decir, la pura ejecución geométrica y constructiva de las formas. A diferencia, otras zonas que deben ser respetadas, pues vibra en ella toda una evocación individual de elementos que gozan de una particular "lámpara ruskiniana" de la vida, bastante independiente de la concepción

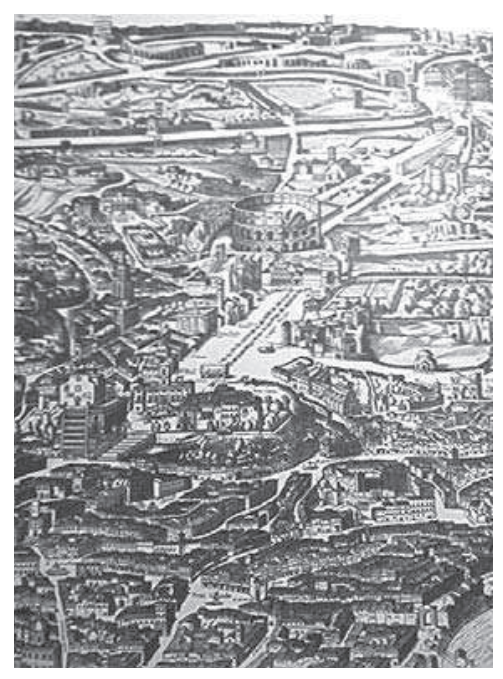

5. ANTONIO TEMPESTA, stampata por Giovanni GIACOMo DE Rossi alla PACE, Vista de Roma en la zona del Colosseo, 1693. arquitectónica general.

Efectivamente, mucho se ha debatido hasta ahora sobre el discurso del tema de la devastación de las ciudades y la necesidad de atender a su reparación y restitución, así como la cuestión del ambiente ha sido exagerada en mil discusiones. Italia no ha sido nunca rígidamente unitaria en tradiciones y formas arquitectónicas (y en ello radica su maravilloso carácter); ha tratado siempre de responder a las condiciones ambientales que se le ofrecían. Los antiguos tenían el sentimiento de arte en sí, sin fricciones con los estilos pasados, y por ello obtuvieron armonía ambiental. De hecho, el primer tema que la Ciencia Urbanística consigna a la Arquitectura, es conservar todo lo que existe en torno a un monumento o bien a grupos ambientales, para obtener así la mejora desde el interior de las manzanas mediante el sistema de que cualquier construcción ex - novo queda subordinada por masa, estatura y color a las viejas construcciones. Los valores del recuerdo insertos en la vida ciudadana, es decir, los monumentos y barrios que subsisten todavía como partes características y vitales de la ciudad, deben en todo lo posible respetarse, evitando la construc-

32 GIOVANNONI, G.: “Vecchie città... Op. Cit., pág. 27 
ción de nuevas vías, nuevos espacios y nuevos movimientos de las estructuras. No obstante, Giovannoni defiende el derecho a crecer del estilo moderno de arquitectura, pero como cualquier otra manifestación artística de nuestro tiempo, distinguiendo entre ésta y aquélla burda edilicia metida en la especulación y en el propio interés que viola las relaciones naturales entre las masas constructivas 33 :

"...la arquitectura menor es la herencia, a través de la cual, diversos tiempos y estilos, lo que llamamos "el espíritu de la ciudad", se han fabricado en unas determinadas condiciones permanentes de clima, materiales y hábitos; es la más cualificada a reencontrar las calidades del ambiente propias para darse, o de otra manera o hubiera existido. Se puede decir que ésta "sobrevive" a los avatares del tiempo. La cuestión es que ahora en las facultades de Arquitectura se preste atención a ellas para redescubrirlas e interpretarlas"34.

A tenor del discurso anterior, subyace la entrada en juego del método positivo para abordar los estudios de arquitectura. Transformar y renovar a través de la precisa comprensión de los monumentos locales, no sólo de los más destacados y nobles, sino también -y especialmente- de los más humildes, pues éstos se hallan en más íntimo contacto con el carácter étnico y en ellos encuentran directa y simple expresión los elementos permanentes 35 .

"...Nada más lejano del ilógico "sventramento" que esta tan de moda como razón de higiene (...). "Las radicales transformaciones de tipo neroniano (reconstrucción después de todo raso al suelo) resultan de bárbaras36", "II tema da architettonico diviene qui urbanístico e la composizione da isolata si amplia a divenire collettiva". 37.

A nivel teórico, entre 1911 y 1913 encontramos los primeros fundamentos de lo que llegarán a ser las primeras disposiciones de la teoría del diradamento ambiental que vendrán a publicarse en Nuova Antologia ${ }^{38}$. Desde el lado administrativo

33 Con motivo del reciente Congreso de los superintendentes publicado en la revista L'Arti, ott-nov en 1942, Marino Lazzari reproduce en parte la Carta del Restauro 1931, referido a las varias fases de respeto de las cosas de arte que son superpuestas, a su manutención y a la prudente consolidación.

34 GIOVANNONI, G.: "Restauro dei monumenti e urbanistica". en Palladio, $n^{\circ}$ 2-3, XXI, Roma, 1943, pág. 38.] Con lo cual, el carácter local debe convertirse en el sustrato de las nuevas manifestaciones arquitectónicas, la nueva arquitectura vernácula.

35 GIOVANNONI, G.: Gli architetti... Op. Cit., págs. 23-24.

36 GIOVANNONI, G.: "Vecchie città... Op. Cit., págs. 29-30.

37 (El tema arquitectónico se convierte aquí en urbanístico y la composición, de aislada, se amplía a colectiva)GIOVANNONI, G.: "La zona del Colosseo ed il suo assetto defiitivo", Capitolivm. Rassegna mensile de Governatorato, Roma, 1937 , pág. 206. 
2: artículos La gestión de la cindad histórica en la Roma Fascista 1...

diseña unas líneas estratégicas para acometer la restauración no sólo de edificios monumentales, sino también de los edificios de arquitectura menor que constituyen su entorno, poniendo de manifiesto la dualidad del problema de los centros históricos: de un lado la proyección urbanística, y del otro, la tutela y valorización de la arquitectura. Giovannoni propone como pionera la adopción de este sistema en el Quartiere del Rinascimento, con ocasión de la reconstrucción llevada a cabo después de la II Guerra Mundial, que ocasionaron la liberación de zonas arqueológicas y la apertura de visuales que en fecha posterior era absurdo eliminar. Tras los bombardeos de la guerra, el peligro de derribo indiscriminado de las construcciones capitaneadas por la especulación era inminente. El organismo arquitectónico de la vieja Roma tenía su propia lógica e higiene y hasta el siglo XIX, todavía eran legibles las estructuras urbanas Las calles eran estrechas y las casas, de escasa altura y generalmente unifamiliares hasta el siglo XVII. Entre las manzanas se localizaban vastísimos espacios abiertos, organizados por jardines y dotados de correctas condiciones de salubridad e higiene, ya que el aire penetraba a través de ellos.

En contraposición, el desordenado urbanismo decimonónico fomentó la elevación de los edificios en dos o tres pisos, y aquellos que antes eran residencia de nobles o burgueses, ahora eran habitados por artesanos, los cuales no podían alejarse del viejo centro y subdividían las viviendas en múltiples habitaciones sin tabiques, luz ni higiene ${ }^{39}$.

La teoría consistía en considerar la cuestión de la viabilidad, integrando normas y disciplinas de construcción en la zona y promover restauraciones sistemáticas de las casas aisladas, intercalándolas en el sistema urbano. El proyecto del diradamento reducía al mínimo las nuevas construcciones orgánicas de nueva planta, prevaleciendo el criterio del máximo aprovechamiento, demoliendo los añadidos superfluos y reabriendo visuales escondidas, tratando de evitar en lo posible el trazado de nuevas vías. Se unían en cambio, la valorización artística y la funcionalidad en una solución única, que mantenía el esquema urbanístico del barrio; disminuyendo la densidad edificativa y mejorando las condiciones de habitabilidad e higiene 40 . El diradamento edilizio como método eficaz, tenía que ser afrontado metódicamente y con unidad de acción en toda las zonas donde existiese un vínculo armónico, el cual liga la obra de arte a su cuadro natural o construido, y evoca nociones de uni-

38 GIOVANNONI, G.: “Il 'diradamento' edilizio dei vecchi centri. II quartiere della Rinascenza in Roma”, en Nuova Antologia, XLVIII, № 997, I julio, 1913.

39 Los famosos appartamenti romanos. GIOVANNONI, G.: "Il diradamento edilizio ed i suoi problemi nuovi", en Urbanistica, Revista dell'Istituto Nazionale di Urbanistica, Anno XII, $n^{\circ}$ 5-6, septiembre-diciembre, Roma,1943, pág. 4.

40 GIOVANNONI, G.: "Sistemazione edilizia del quartiere del rinascimento a Roma. Relazione della Commissione all'Onorevole Consiglio Comunale", en Relazione della Commissione all'Onorevole Consiglio Comunale, Roma, 1919, págs. 18-19. 
dad y continuidad del ambiente: "L'ambiente (...) elemento intrinseco della composizione architettonica. Un'opera d'arte, e specialmente un'opera architettonica, non vive orgogliosamente isolata, ma si accacia sulla via in una serie continua con altre opere da cui riceve riflessi e limitazioni di misure, di colore, di ornamento"41. A partir de ese momento la noción de ambiente vendrá recogida en la legislación italiana a través de normativas específicas que conjugarán el elemento arquitectónico y el natural.

Por otro lado, la política de protección pública del patrimonio histórico, artístico, arqueológico y arquitectónico, es decir, el complejo de Bienes Culturales (muebles e inmuebles) es desarrollada integralmente por vez primera a través de una disciplina general en la Ley de 1 de junio de 1939, $n^{\circ} 1089$ y atendía a la "tutela de las cosas de interés artístico e histórico" hasta la derogación que tuvo lugar con la nueva D.Lgs. 29 de octubre de 1999. $n^{\circ}$ 49042. Este documento introdujo bastantes innovaciones con particular referencia al ámbito de tutela pública, que se extendió a los bienes de interés histórico, artístico y arqueológico, excluyendo aquellas obras producidas por autores vivos $\mathrm{o}$, tras transcurrir cincuenta años después de su muerte. En Giovannoni se asiste al reconocimiento en la legislación -hasta entonces inexistente- del argumento de ambiente, pues es precisamente a partir de este momento cuando se establece la distinción entre manifestaciones colectivas y singulares, confiriendo legislador el mérito de valorar las relaciones existentes entre una obra monumental y aquéllas que la circundan.

En otro orden de cosas, durante el período fascista la reconstrucción de los centros destruidos por la guerra no representaba solamente un tema de técnica constructiva. Éstos debían ser considerados como un argumento del arte italiano, del sentimiento italiano; argumento vivo, donde se conectaban los sagrados deberes que las autoridades proponían para la reconstrucción. En este sentido, las tesis de

41 "El ambiente (...) elemento intrínseco de la composición arquitectónica. Una obra de arte, es especialmente una obra arquitectónica, no vive orgullosamente aislada, aunque se suceda en el camino en dirección conténua con otras obras de las cuales recibe influencias y límites de proporción, de color, de ornamentación". ZUCCONI, G. (a cura di): Gustavo Giovannoni: dal capitello alla città, Jaca Book, Como, 1997, pág. 44.

42 Durante el período de los Estados Individuales pre-unitarios tuvieron lugar iniciativas legislativas que atendieron a la protección y tutela de Bienes Culturales. Sin embargo, en presencia de una notable producción de disposiciones de parte de los diversos papas y soberanos, no se registró ningún resultado concreto a favo de intervenciones públicas que tutelasen y expropiasen aquellos bienes a favor del disfrute de la colectividad. En cierto modo, influidos por la ideología liberal ochocentesca, que consideraba un abuso cualquier intervención pública que condicionase la comerciabilidad de los bienes de propiedad privada. Posteriormente, tras la ción pública que condicionase la comerciabilidad de los bienes de propiedad privada. Posteriormente, tras la constitución del Estado Unitario Italiano, la primera ley que intenta disciplinar el uso y conservación de las cosas de interés histórico, artistico y arqueológico fue la Ley de 12 de junio de 1902, n 185 . La Ley de 2 de junio de 1909, $n^{\circ} 364$, cuyo coordinador y compilador fue Corrado Ricci, responsable de la redacción ministerial Esta ley fue ulteriormente mejorada con decretos sectoriales relativos al Reglamento de ejecución de la ley de 1909 (R.D. 30 de enero de 1913, $n^{\circ} 363$ ); la confección de un Catálogo de monumentos y cosas de interés histórico, artístico y arqueológico (R.D. 31 de diciembre de 1923, $n^{\circ} 1889$ ); la Custodia, conservación y contabilidad del material artístico, arqueológico, bibliográfico y científico (R.D. 26 de agosto de 1927, $n^{\circ}$ 1917), entre otros. 
6. Demolición de las casas del foro de Augusto para la construcción de la Via del Mare, 1932. Fotografia: Istituto Luce.

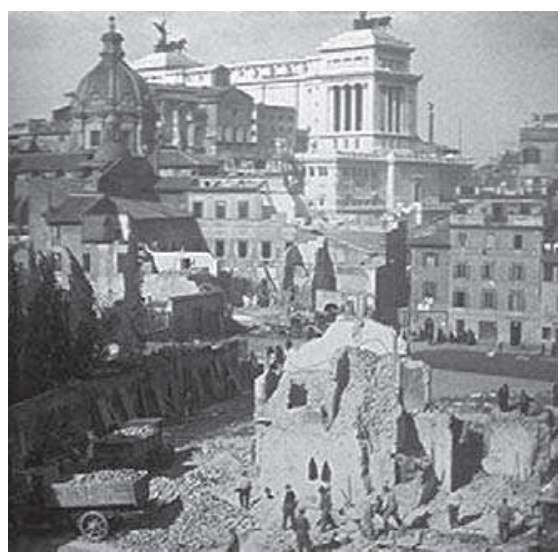

Giovannoni demuestran cierta parcialidad y señalan el principio del declive de su autoridad y poder frente al de las instituciones mussolinianas. El clima académico y fascista dominado por la convergencia de intereses entre grupos políticos de extrema derecha, la aristocracia romana monopolizadora de la actividad constructiva y los arquitectos tradicionalistas y conservadores, ignoraron por completo el teórico horizonte urbanístico, se anuló por completo la autonomía del Comune en materia urbanística y se confirieron a los regidores estatales poderes especiales y absolutos que canalizaron la base del Piano Regolatore hacia los llamados sventramenti (desmembramiento o disgregación de las estructuras urbanas):

"Qui si sente davvero l'urgenza del piccone! ${ }^{43}$ [6].

El proceso de centralización de los poderes ejecutivos en el interior de la maquinaria administrativa se realizó a todos los niveles de la organización pública. Se procedió al progresivo desmantelamiento de los aparatos burocráticos; los sindicatos y los consejos comunales fueron sustituidos por el Governatorato (1925-1944), organismo a través del cual se resolvieron en tiempo record los problemas funcionales de la ciudad. El Gobierno procedió a instaurar comisarios en nómina dotados de poderes extraordinarios, y un ingeniero-jefe controlaba bajo su influencia los destinos de la ciudad, en la que no se anteponía ningún obstáculo al desarrollo de los proyectos lanzados desde la cúpula del régimen 44 .

43 "iAquí se siente verdaderamente la urgencia de la piqueta!". MASTRIGLI, F.: I XXIII rioni della Roma di Mussolini, II lavoro fascista, Roma, 1938.

44 ZUCCONI, G.: Op. Cit., págs. 135-138, y 142-143 


2: artículos Belén Calderón Roca

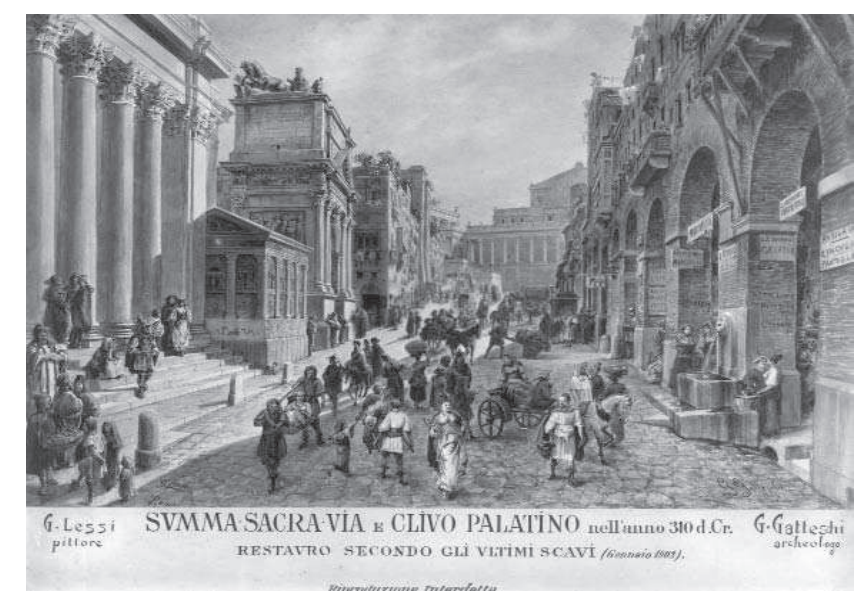

7. Restos del foro romano y Palatino (Summa Sacra Via e Clivo Capitolino) en el 310 d.C. Anónimo 1902. Archivio Storico Capitolino (Roma).

En los años treinta y sólo por directa voluntad del Duce, impera la máxima de exhibir la solemne conciencia del pasado y la majestuosidad del Imperio, haciendo girar la vida ciudadana en torno a los restos físicos de la antigüedad gloriosa del Imperio Romano [7]. En materia urbanística, el período de dominación fascista se caracterizó por una notable evolución del concepto de piano regolatore (plan de ordenación). Se manifestó una conciencia general sobre la necesidad de dotar de un Plan a la ciudad que sirviese para regir sus procesos de transformación y expansión. En este sentido, la Ley 24 de marzo de 1932, no 355, del Piano Regolatore de Roma contenía muchos principios, normas y prescripciones que caracterizarían diez años después a la primera ley urbanística general: la Ley 17 de agosto de 1942, $n^{\circ} 1150$. Esta normativa representó el primer ordenamiento sistemático de órganos y medios para disciplinar el uso del territorio. Clara y bien estructurada en finalidad y contenidos, fue bastante avanzada respecto a las líneas y tendencias europeas de la época en materia urbanística y sólo quedaba empañada por la desconexión entre los recursos financieros y la activación de los planes. No obstante, en la práctica, los años que duró el Governatorato significaron un importante suceso en la gestión urbana de Roma. La ciudad apareció como el escenario perfecto para emprender los postulados de la dictadura fascista. El Piano Regolatore de 1931 [8], constituyó el máximo 


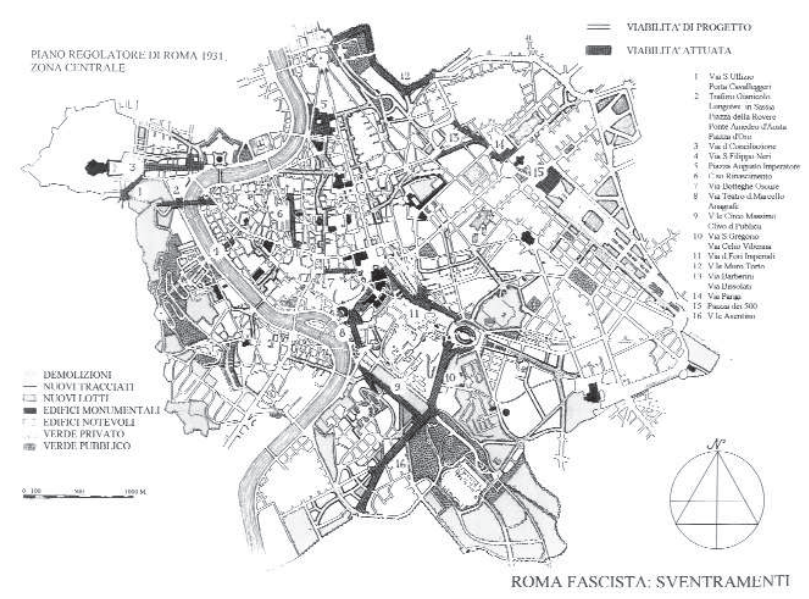

8. Sventramenti en la Roma fascista. Piano Regolatore di Roma 1931.

esfuerzo urbanístico del régimen de Mussolini, que nació sin la compresión verdadera del destino urbanístico de la ciudad. Resulta vital someter a análisis aquel momento pleno de principios teóricos que no se ajustaban a una práctica disciplina de control urbanístico y fortísimas reestructuraciones de los tejidos históricos, impulsada a través de criterios de risanamento (regeneración) higiénico y ambiental, además de elogios patrióticos [9] No obstante, el plan de 1931 resultó continuamente impugnado y rectificado. En definitiva, la multitud de planos particularizados constituyeron la única unidad de actuación efectiva del documento, así como de real transformación de la ciudad.

Una de las zonas de gran relevancia en el Piano Regolatore de 1931 en torno a la cual giraba toda la movilidad de Roma era la zona que abarcaba desde la Piazza Venezia hasta el Colosseo [10]. La idea esencial consistía en restituir a esta área del Campidoglio su carácter y significado de antaño, liberando al Colle Capitolino de las antiestéticas construcciones de nueva fábrica que distorsionaban aquel ambiente, resolviendo además, los numerosos problemas de uso que existían en aquel período. Las decisiones se toman desde la Commissione dei Monumenti (de la cual formaba parte Giovannoni) mediante una iniciativa tomada del Ministero per i Lavori Pubblici, de acuerdo con el Comune di Roma y el Ministero della Pubblica Istruzione. 


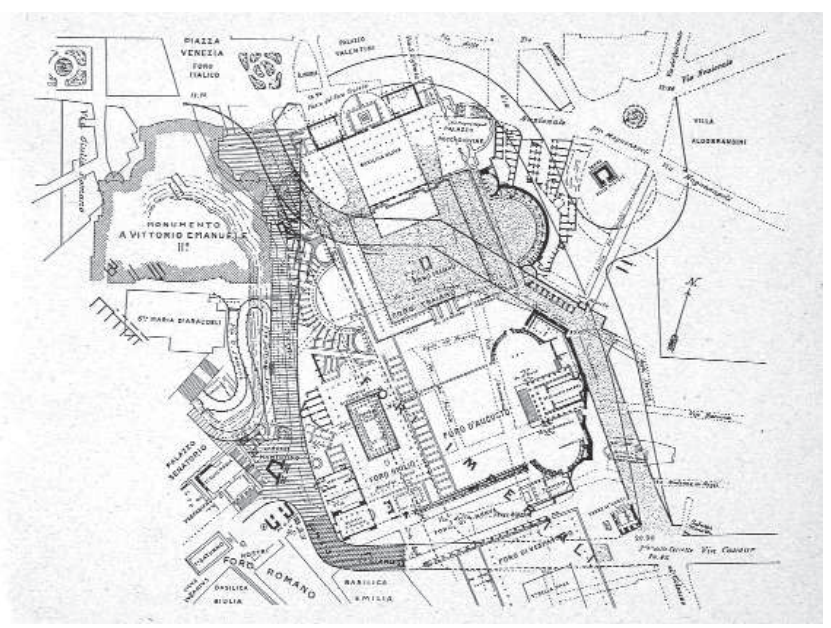

9. GIOVANNONI, Plano de la reordenación del Colle Capitolino.

Era fundamental mantener la idea de los hombres del Medievo de que el Campidoglio era el caput mundi, centro máximo de la vida política de Roma y símbolo glorioso del pensamiento latino. En ella convergerían la mayor parte de las arterias nuevas o modernos trazados como la Via del Imperio, la Via de los Triunfos, o la Via San Giovanni in Laterano.

En torno a la historia de este monumento se han llevado a cabo diversas tentativas urbanísticas, aunque desde diversas ópticas. Una de las más interesantes fue el trazado de la gran Vía del Imperio, partiendo de los mismos conceptos que en el transcurso de los siglos I a.c. hasta finales del siglo I d.C. se hicieron los foros. En el Piano Regolatore ejecutado a final del XVI hasta los preceptos megalómanos de Sixto V, la gran calle de San Giovanni era prevista como un eje patrón para unir esta parte de la ciudad con el Campidoglio. En época napoleónica se aísla y queda como punto de referencia de la ciudad, sustituyendo los vicoli o callejones estrechos y tortuosos, formando así un escenario solemne 45 .

45 GIOVANNONI, G.: "La zona del Colosseo...Op. Cit. pág. 203. Vid. a.: GIOVANNONI, G.: Relazione sulla sistemazione edilizia del Colle Capitolino e delle sue adiacenze, E. Calzone Editore, Roma, Estrato dal Bolletino del Ministero della Publica Istruzione. Anno XIV, N.5-8, Maggio-Agosto 1920 


\section{- E artículos La gestión de la ciudad histórica en la Roma Fascista 1...}
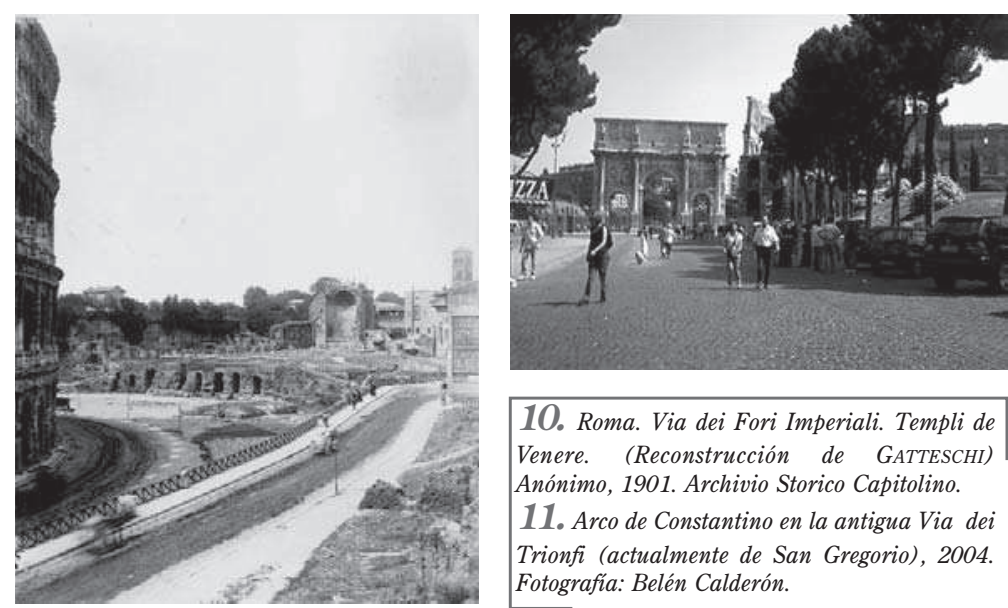

10. Roma. Via dei Fori Imperiali. Templi de Venere. (Reconstrucción de GATTESCHI) Anónimo, 1901. Archivio Storico Capitolino.

11. Arco de Constantino en la antigua Via dei Trionfi (actualmente de San Gregorio), 2004. Fotografía: Belén Calderón.

Sin embargo, por otra parte, existía además un gran complejo arqueológico que dividía la zona central de Roma, quedando el monumento en medio de visuales, trazados y de la circulación de la zona. Antes de abrirse la gran Via dei Fori Imperiali (llamada antiguamente Via dell'Impero) al Coliseo se llegaba descendiendo desde la reducida y estrecha Via del Colosseo (desde el Palacio Sangallesco y desde la villa del Cardenal Pio ).

La nueva avenida se construyó al nivel de la platea del anfiteatro, y en torno a éste un vasto sistema de circulación rodada conectaba las calles que se dan cita tangencialmente: Via dell'Impero, Via Labicana, Via Claudia y Via dei Trionfi (actual Via di San Gregorio) [11]. Ésta resultó interrumpida entre el antiguo espacio en el cual convergían el arco de Constantino y el templo de Venus, y la zona superior (Esquilino y Appio) [12]. Giovannoni atiende a la necesidad de mejorar la apreciación del monumento, sobre todo en el lado NE (el de mejor conservación) con lo cual, una zona de la sistemazione que afectó directamente al ambiente es aquella del piazzale del SE, enclave destinado desde el Piano Regolatore de 1931 a ser notablemente ampliado con construcciones nuevas que sustituyesen a las viejas y donde confluían grandes corrientes de tráfico. Las zonas circundantes al Coliseo -en la mayoría arqueológicas- en las cuales el ambiente resultaba aún más sugestivo, exigían que la arquitectura de los nuevos edificios fuese estudiada con criterio unitario, ya fuese en relación con el ambiente del monumento antiguo, que con la que afectaba a la nueva calle, evitando que las nuevas zonas intermedias constituyesen 


Q: artículos $\quad$ Belén Calderón Roca

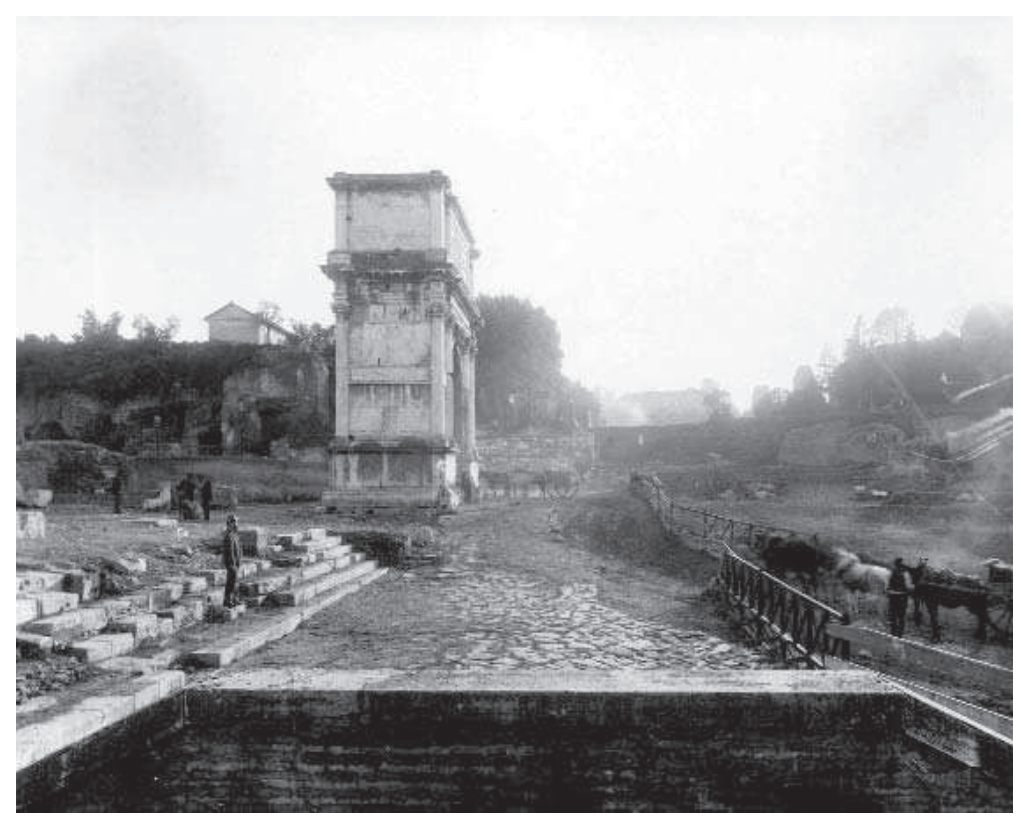

12. Palatino. Summa Sacra Via con el Tempio Giove en el 310 d. C. Anónimo 1902. Reconstrucción de GATTESCHI). Archivio Storico Capitolino.

una nota discordante. Del mismo modo, adelanta el grave problema que años más tarde amenazaría gravemente la integridad de los vestigios y constituirían un peligro para la integridad del monumento: el tráfico circulante por Via dell'Impero. En cualquier caso, el Comitato Urbanistico del Governatorato di Roma desatendió sus peticiones.

\section{Conclusiones.}

Las tentativas investigadoras italianas destinadas a la restauración arquitectónica de los centros históricos a partir del período post-bélico, y que en la actualidad constituyen un campo de debate dialéctico permanente, son deudoras en gran medida de las experiencias investigadoras de Gustavo Giovannoni en Roma durante un 
2: artículos La gestión de la ciudad histórica en la Roma Fascista 1...

período de ajetreo político y social que fluctúa entre la Italia liberal de la primera veintena del Novecientos y la Italia fascista de la segunda.

La figura de Giovannoni supuso un elemento clave en la constitución de la Escuela de Arquitectura de Roma y ésta resultó determinante para el estudio de la historia de la arquitectura, la urbanística y la restauración de monumentos en el contexto italiano. La primera escuela nació en un periodo liberal, no obstante, durante el fascismo, en presencia de un régimen autoritario, se acentuaron las connotaciones ideológicas y la arquitectura se convirtió para el fascismo en un arma, de entre las más eficaces para obtener el beneplácito político.

Quizás podríamos afirmar que nuestro autor encarna al primer y verdadero teórico del restauro urbano desde el punto de vista de la historiografía. Giovannoni conduce su trayectoria didáctica hacia una precisa y fundamental orientación: la salvaguardia del patrimonio monumental y la valoración de la figura profesional del arquitecto, cuya formación histórica resulta incuestionable e imprescindible en los estudios de Arquitectura como punto de partida para establecer los criterios de actuación en la profesión.

Para concluir, el Giovannoni urbanista se forja en una intrincada confluencia de ideas, teorías, y hábitos, adelantándose a sus contemporáneos con el razonamiento de que la restauración urbana en sí misma no está provista de sentido y valoración objetivos y definitivos, afirmando que de hecho, ésta no puede identificarse con una disciplina homogénea. De ahí que la lectura gráfica de los espacios culturales urbanos pueda provocar incertezas, cuando los elementos a tutelar presentan dimensiones ambientales, paisajísticas o antropológicas.

La agotadora labor de documentación con la que en múltiples ocasiones se obtienen resultados parciales se resolvería a través de relecturas y la extensión ilimitada de la fase del análisis, articulando las relaciones con el pasado como un proceso de continuidad que no sólo afectaría a los objetos, sino también a las circunstancias en las cuales éstos se manifiestan. Las múltiples interpretaciones de la realidad urbana conducirán sin duda a clarificar su legibilidad. 
